\title{
Intervensi Massage dan Kinesio Tapping menurunkan Nyeri Musculus Hamstring
}

\author{
Massage and Kinesio Tapping interventions reduce Hamstring Muscle Pain
}

\author{
Suharto, Darwis Durahim, Sri Saadiyah Leksonowati \\ Jurusan Fisioterapi Poltekkes Makassar
}

Koresponden : suhartoft11@gmail.com

\begin{abstract}
ABSTRAK
Cedera pada hamstring umumnya terjadi karena adanya kerentanan atau kesalahan pada posisi anatomi. Pada pemain futsal kebanyakan terjadi cedera strain hamstring pada saat lari biasa dan lari cepat atau sprint. Tujuan penelitian ini untuk mengetahui pengaruh Massage effleurage dan Kinesio Tapping terhadap perubahan nyeri musculus hamstring pada pemain futsal. Penelitian ini adalah pre-experimental dengan desain one group pre test - post test. Sampel penelitian ini pasien yang mengalami nyeri musculus hamstring sehabis bermain futsal diberikan Massage effleurage dan kinesio tapping selama 4 minggu dengan frekuensi pemberian 2 kali seminggu. Alat ukur penelitian ini adalah VAS. Hasi uji wilcoxon menunjukkan bahwah ada pengaruh pemberian Massage effleurage dan Kinesio tapping terhadap perubahan nyeri musculus hamstring pada pemain futsal diperoleh nilai $p(0,003)(p<0,005)$. Kesimpulan hasil dari penelitian ini adalah Massage dan Kinesio tapping dapat menurunkan nyeri musculus hamstring. Disarankan kepada pemain futsal agar memberikan massage dan menggunakan tapping apabila terajadi cedera otot hamstring akibat bemain futsal.
\end{abstract}

Kata Kunci : Massage, Kinesio tapping, musculus hamstring

\section{ABSTRACT}

Injuries to the hamstring generally occur due to vulnerabilities or errors in anatomical position. In most futsal players, hamstring strain injuries occur during regular running and sprinting or sprinting. The purpose of this study was to determine the effect of Massage effleurage and Kinesio Tapping on changes in hamstring muscle pain in futsal players. This research is a pre-experimental design with one group pre test - post test. The sample of this study was patients who experienced hamstring muscle pain after playing futsal were given massage effleurage and kinesio tapping for 4 weeks with a frequency of 2 times a week. The measuring instrument of this research is the VAS. The results of the Wilcoxon test showed that there was an effect of giving Massage effleurage and Kinesio tapping on changes in hamstring muscle pain in futsal players, with a $p$ value (0.003) ( $p$ 0.005). The conclusion of this research is massage and kinesio tapping can reduce hamstring muscle pain. It is recommended for futsal players to give massage and use tapping if there is a hamstring muscle injury due to playing futsal.

Keywords: Massage, Kinesio tapping, hamstring muscles

\section{PENDAHULUAN}

Semua aktivitas manusia termasuk olahraga penuh dengan risiko atau bahaya. Seiring dengan meningkatnya aktivitas olahraga meningkat pula risiko atau bahaya tersebut salah satunya cedera otot (Sukarmin, 2005).

Cedera otot yang paling sering adalah otot hamstring, hal ini terjadi karena sering menunjukkan terjadinya muscle cramps (kejang otot) sampai terjadinya rupture otot (sobekan otot) dan terjadinya Delayed Onset Muscle Soreness dan partial strain injury. Cedera pada hamstring umumnya terjadi karena adanya kerentanan atau kesalahan pada posisi anatomi. Pada pemain sepakbola atau futsal kebanyakan terjadi cedera strain hamstring pada saat lari biasa dan lari cepat atau sprint (Suriani.S 2016).

Penelitian menyebutkan cedera hamstring terjadi di saat fase kaki mengayun (Swing Phase), ketika hamstring bergerak ke ekskinesiotappingi knee dan terjadi pemanjangan otot hamstring bekerja secara eksentrik dan kontraksi konsentrik terjadi saat ekskinesiotappingor hip. Jadi cedera terjadi karena adanya gerakan dan perubahan kontraksi eksentrik ke kontraksi konsentrik (Suriani.S 2016).

Otot hamstring dapat terkena cedera secara tiba tiba, nyeri pada belakang paha dan sampai menyebabkan aktifitas terhambat. Setelah cedera knee tidak bisa melakukan gerakan ekskinesiotappingi lebih dari 30 - 40 derajat . Cedera hamstring 
banyak terjadi pada lipatan bagian posterior yang dapat menghentikan aktivitas latihan atau olahraga. Tetapi tidak hanya adanya tarikan pada posterior otot yang bisa mengakibatkan cedera hamstring, adanya nyeri otot juga merupakan salah satu tanda terjadinya cedera pada hamstring karena adanya kerusakan pada jaringan fibrous ( Suriani.S 2016).

Sementara itu salah satu metode non farmakologis yang merupakan metode pendukung dalam mengurangi nyeri yaitu dengan Massage Effleurage yang dapat memberikan manfaat seperti memberikan rasa nyaman, rileksasi mengurangi atau membebaskan rasa nyeri ( Sari dan Susilowati, 2016).

Terapi lain yang juga bisa digunakan untuk mengurangi gejala nyeri pinggang bawah adalah kinesio tapping. Kinesio taping digunakan untuk mengurangi nyeri, meningkatkan lingkup gerak sendi (LGS), mensupport fungsi sendi, mengaktifasi sistem limfatik dan sistem endogen analgesik, meningkatkan mikrosirkulasi dan efek fungsi otot. Kinesio taping mengalami puncak pengaruh setelah 24 jam pemakaian dan akan menurun fungsinya setelah 4 hari (wahyuni dan prabowo, 2012).

Dikutip dari Sport sinjury bulletin kerusakan otot paling banyak terjadi di bagian paha (groin) yakni $53 \%$. Otot lain yang sering sobek dalam permainan sepakbola/futsal adalah hamstring (42\%) dan quadriceps atau otot paha di sisi depan (5\%) ( Guspriadi, 2013).

Berdasarkan latar belakang masalah diatas tentang ada nyeri musculo hamstring yang timbul sehabis permainan futsal, maka peneliti merumuskan pertanyaan "Apakah ada pengaruh Massage effleurage dan Kinesio tapping terhadap perubahan nyeri musculus hamstring pada pemain futsal di Indomaret FC ?" sehingga tujuan penelitian ini adalah untuk mengetahui adanya pengaruh Massage effleurage dan Kinesio tapping terhadap perubahan nyeri musculus hamstring pada pemain futsal di Indomaret FC.

\section{PROSEDUR DAN METODE Jenis Penelitian}

Penelitian ini dilaksanakan pada pemain futsal yang mengalami nyeri Musculu Hamstring sehabis bermain futsal Indomaret FC.

Penelitian ini adalah penelitian preexperimental. Penelitian pre-experimental ini dimaksudkan untuk menggambarkan perubahan nyeri terhadap pemberian massage effleurage dan kinesio tapping. Desain penelitian yang digunakan adalah "one group pretest-posttest design ".

\section{Populasi dan Sampel}

Dalam penelitian ini populasi yang digunakan adalah semua pemain futsal yang berstatus aktif dalam latihan minimal 2 kali seminggu selama satu bulan setelah observasi dilakukan pada pemain futsal Indomaret FC di Indoor Pagodam Daya Makassar. Pengambilan sampel dilakukan secara purposive sampling. Dalam penelitian ini sampel yang digunakan adalah pemain futsal yang memenuhi kriteria inklusi.

\section{Kriteria Insklusi}

1. Pemain futsal yang mengalami cedera olahraga setelah latihan yaitu nyeri musculus hamstring.

2. Bersedia menjadi responden.

\section{Kriteria Eklusi}

1. Tidak mengalami nyeri Musculus Hamstring.

2. Memiliki penyakit bawaan lain.

3. Mengundurkan diri menjadi responden.

\section{Besar Sampel}

Sampel penelitian yang diperoleh menggunakan tehnik pengambilan purposive random sampling yaitu 10 orang yang mengalami nyeri Musculo Hamstring pada pemain futsal Indomaret FC.

\section{Prosedur Pengumpulan Data}

Pengumpulan data dilakukan pada awal penelitian dan akhir penelitian sebagai data pre-test dan post-test. Adapun 
pengukuran yang digunakan sebagai pretest dan post-test adalah :

1. Alat yang digunakan: alat Visual Analog Scale (VAS).

2. Pelaksanaan

a. Menjelaskan garis Visual Analog Scale, dimana di awal garis tidak ada nyeri pada akhir garis merupakan nyeri tak tertahankan.

b. Pasien di intruksikan untuk mendandai garis tersebut sesuai nyeri yang ia rasakan.

c. Evaluasi Kriteria Objektif Nyeri:

1) $0:$ Tidak Nyeri

2) 1-3: Nyeri ringan

3) 4-6 : Nyeri Sedang

4) 7-9 : Sangat nyeri, tapi masih sangat di control.

5) 10 : Sangat nyeri dan tidak bias dikontrol.

\section{Prosedur Pelaksanaan Intervensi}

Intervensi yang diberikan pada kelompok perlakuan adalah massage effreurage dan kinesio tapping.

1. Prosedur pelaksanaan massage effreurage

a. Menjelaskan prosedur yang akan dilakukuan kepada pasien.

b. Di anjurkan pada pasien pada posisi nyaman dengan posisi tidur terlentang lalu kaki disanggah dengan bantal agar pasien rileks.

c. Kemudian dilakukan gerakan tehnik effreurage dengan kedua telapak tanggan dengan sentuhan ringan pada musculus hamstring. Dilakukan $8 x$ pengulangan setiap gerakan dengan waktu 10-15 menit.

2. Prosedur pelaksanaan kinesio tapping

a. Area yang akan diberikan tapping di bebaskan dari Pakaian atau benda lain

b. Area yang akan di pasangkan tapping harus dibersihkan dari minyak dan lation

c. Responden diposisikan dengan berdiri lalu taping dipasangkan pada otot hamstring sampai 3 hari. $\mathrm{Di}$ lakukan sebanyak $2 x$ seminggu selama 4 minggu.

\section{Hipotesis Penelitian}

Ada pengaruh pemberian massage effleurage dan Kinesio tapping terhadap perubahan nyeri musculus hamstring pada pemain futsal di Indomaret FC di Indoor Pagodam Daya Makassar.

\section{Analisis Data}

Dalam mengelolah data penelitian yang diperoleh, maka penelitian menggunakan Uji Statistik Wilcoxon.

\section{HASIL PENELITIAN}

Tabel 1. menunjukkan bahwa umur $21-23$ berjumlah 5 respoden atau $50,0 \%$, sedangkan responden yang berumur $24-26$ tahun berjumlah 5 responden atau 50,0\%.

Pada tabel. 2 Hasil analisis uji statistik wilcoxon menunjukkan nilai perbedaan nyeri sebelum dan setelah pemberian massage effleurage dan pemasangan kinesio tapping $2 \times$ seminggu selama 4 minggu dengan nilai $p(0,003)(p<0,005)$ artinya ada pengaruh pemberian massage effleurage dan pemasangan kinesio tapping terhadap perubahan nyeri musculus hamstring pada pemain futsal.

\section{PEMBAHASAN}

Hasil menunjukkan bahwa umur 21 23 berjumlah 5 responden atau 50,0\%, sedangkan responden yang berumur 24 - 26 tahun berjumlah 5 responden atau 50,0\%.

Cedera otot hamstringpada pemain futsal terjadi karena terjadinya muscle cramps (kejang otot) sampai terjadinya rupture otot (sobekan otot), dan terjadinya Delayed Onset Muscle Soreness dan partial strain injury. Cedera pada hamstring umumnya terjadi karena adanya kerentanan atau kesalahan pada posisi anatomi. Penelitian menyebutkan cedera hamstring terjadi di saat fase kaki mengayun( Swing Phase), ketika hamstring bergerak ke ekskinesiotappingi knee dan terjadi pemanjangan otot hamstring bekerja secara eksentrik dan kontraksi konsentrik terjadi saat ekskinesiotappingor hip. Jadi cedera 
terjadi karena adanya gerakan dan perubahan kontraksi eksentrik ke kontraksi konsentrik. Otot hamstring dapat terkena cedera secara tiba tiba, nyeri pada belakang paha dan sampai menyebabkan aktifitas terhambat.

Hasil analisis uji statistik wilcoxon menunjukkan nilai perbedaan nyeri sebelum dan setelah pemberian massage effleurage dan pemasangan kinesio tapping $2 \mathrm{x}$ seminggu selama 4 minggu dengan nilai $p$ $(0,003)(p<0,005)$ artinya ada pengaruh pemberian massage effleurage dan pemasangan kinesio tapping terhadap perubahan nyeri musculus hamstring pada pemain futsal. Hasil penelitian ini sejalan dengan penelitian Arizal RP ( 2013) yang menyatakan bahwa ada pengaruh massage terhadap penurunan delayed onset muscle soreness shoulder pada olahraga badminton). Uji statistic menggunakan wilcoxon rank test didapat $p 0.012(p<0,05)$ yakni ada perbedaan pengaruh massage antara sebelum dengan sesudah bermain olahraga badminton dalam menurunkan Delayed Onset Muscle Soreness Shoulder.

Kinesio tapping adalah modalitas pengobatan didasarkan pada metode proses penyembuhan secara alami. Kinesio menunjukkan efektivitas melalui aktivasi neurologi, mengakui pentingnya tubuh dan otot serta gerakan dalam rehabilitasi dan kehidupan sehari - hari. Maka modalitas Kinesio tapping digunakan. Otot tidak hanya untuk gerakan tubuh, tetapi juga mengontrol peredaran arus getah bening, temperatur tubuh, dll. Oleh karena itu, jika terjadi kegagalan otot dalam berfungsi dengan baik maka menginduksi berbagai macam penyakit kesehatan. (Kaze, 2013)

Hasil penelitian sebelumnya oleh Fadlan AR (2016) dengan judul pengaruh penambahan kinesio taping pada transverse friction terhadap penurunan nyeri tennis elbow) terdapat pengaruh penambahan kinesio taping pada transverse friction terhadap penurunan nyeri tennis elbow di peroleh nilai $p$ : $0,020(p<0,05)$. Penelitian ini sesuai dengan yang dilakukan pada pemain futsal, karena dengan pemberian masaggeakan menimbulkan rasa tenang , nyaman, rileks, dan mengurangi rasa sakit.Massage dapat menghilangkan atau mencegah terjadinya perlekatan dan scar tissue akibat adanya cairan yang disebut traumatic exudate yang dapat menyebabkan melekatnya serabut otot satu sama lain dan menimbulkan penebalan (thickening). Perlekatan yang menjadi penebalan ini bila telah berlangsung lama sukar dihilangkan, kecuali dengan operasi( Tri Purnomo, 2016).

Pemberian kinesio tapping dan massage effleurage memberikan pengaruh terhadap perubahan nyeri musculus hamstring pada pemain futsal. Pada penelitian ini perlakuan berupa pemberian kinesio tapping dan massageeffleurage dilakukan secara rutin oleh peneliti sehingga semua responden mengalami perubahan terhadap nyeri musculus hamstring pada pemain futsal.

\section{KESIMPULAN}

1. Nilai rata - rata derajat nyeri sebelum pemberian Massage effleurage dan Kinesio tapping terhadap perubahan nyeri musculus hamstring pada pemain futsal sebesar 6,50 $\pm 0,527$.

2. Nilai rata - rata derajat nyeri sesudah pemberian Massage effleurage dan Kinesio tapping terhadap perubahan nyeri musculus hamstring pada pemain

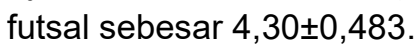

3. Ada pengaruh pemberian Massage effleurage dan Kinesio tapping terhadap perubahan nyeri musculus hamstring pada pemain futsal.

\section{DAFTAR PUSTAKA}

Adjam, Fadli Ramlih., 2016. Pengaruh Penembahan Kinesio Taping Pada TransverseFriction Terhadap Penurunan Nyeri Tennis Elbow. Skripsi. Program Studi Fisioterapi. Universitas Aisyiah Jogja.

Afrianti.W.W., Sukadarwanto. 2016. Pengaruh Fisiotaping Terhadap Peningkatan Kemampuan Fungsional Pada Pasien 
Osteoarthritis. Jurnal Keterapian Fisik, Volume 1, No 1: Page 01-74 Amalia,Ana., Elyana Mafticha. 2012 Jenis Persalinan Dengan Skala Nyeri Involusi Uterus Masa Nifas Di Rsud Prof. Dr. Soekandar Mojosari Mojokerto Jurnal IImiah Kesehatan Politeknik Kesehatan Majapahit. Vol 4 : No. 2

Baharuddin, Moh.2013. Penanganan Cedera Olahraga Pada Atlet (Pplm) Dan (Ukm) Ikatan Pencat Silat Indonesia Dalam Kegiatan Kerjurnas Tahun 2013.

Galuh R. Mufti. Harold F. Tambajong. Diana Lalenoh. 2016. Gambaran skala visual analog dan hemodinamik pada pasien yang diberikan kombinasi tramadol dan ketorolak pasca bedah laparotomi.

Jurnal e-Clinic $(\mathrm{eCl})$, Volume 4, Nomor 1 ,

Guspriadi, Eko. 2013. Cedera dalam sepakbola dan futsal. Tabloid Soccer, edisi 17/XI, www.ueu20126619.weblog.esaun ggul.ac.id/2013/08/27/cederadalam-sepakbola-danfutsal<access at Februari, 27 2017.

Hyun Bae, Sea,. Young-Shin Lee., Gi-Do Kim., Kyung-Yoon Kim. 2014. The Effects Of Kinesio-Taping Applied To Delayed Onset Muscle Soreness On Changes In Pain. International Journal of BioScience and Bio-Technology Vol.6, No.3 (2014)

Mila.J.H., Caecilia.S.W., Yuniar. 2014. Usulan Strategi Minimasi Stres Kerja Pada Pekerja Back Office Bank Jabar Banten Berdasarkan Galvanic Skin Response, Visual Analog Scale, dan NIOSH General Job Stress Questionnaire*.
Jurusan Teknik Industri Itenas: Vol.02. No.2.

M.irfan, Natalia. 2008. Beda Pengaruh Auto Stretching dengan Contract Relax and Stretching terhadap Penambahan Panjang Otot Hamstrin. Jurnal Fisioterapi Indonusa Vol. 8 No. 1, April 2008

Paul M, Taylor, Diene K. Taylor. 2002. Mencegah dan Mengatasi Cedera Olahraga. Jakarta: PT Raja Grafindo Persada.

Sari, Nurvi Alfi., Irfan, M. 2009. Efek Penambahan Taping pada Intervensi Micro Wave Diathermy dan Stretching Terhadap Pengurangan Nyeri pada Kondisi Plantar Fascitis. Jurnal Fisioterapi: Vol. 9 No. 2 p. 3.

Setiawan, Budi., Sulaiman., Rustiana, Raffy, Eunike. 2014. Pengembangan Self Massage dan Terapi Latihan pada Cedera Ankle

(Pergelangan Kaki). Journal Of Physical Education And Sports. Vol 3 No. 1

Sukarmin,Yustinus. 2005. Cedera Olahraga Dalam Persektif Teori Model Ekologi.Jurnal Medikora. Vol 1 : No. 1

Suriani.S. 2016. Mengatasi Doms Setelah Olahraga. Jurnal motion : Vol VII, No.1, 102

Tri, Purnomo, Nowo. 2016. Pijat (Massage) Cidera Olah raga. Semarang: Wahid Hasyim University Press. 
Lampiran :

Tabel 1

Distribusi responden berdasarkan umur

\begin{tabular}{ccc}
\hline Usia & Frekuensi & $\%$ \\
\hline $21-23$ & 5 & 50,0 \\
$24-26$ & 5 & 50,0 \\
Jumlah & 10 & 100,0 \\
\hline
\end{tabular}

Tabel 2.

Analisa nilai aktualisi nyeri sebelum dan setelah terapi terhadap perubahan kasus nyeri musculus hamstring pada pemain futsal di indoor pagodam daya Makassar

\begin{tabular}{|c|c|c|c|c|c|c|}
\hline \multicolumn{2}{|c|}{ Pre test } & \multicolumn{2}{|c|}{ Post test } & \multicolumn{2}{|c|}{ Selisih } & p \\
\hline Mean & SD & Mean & $\mathrm{SD}$ & Mean & $\mathrm{SD}$ & \\
\hline & & & & & & 0,003 \\
\hline
\end{tabular}

